\section{Profile of Intensive Care Unit Admissions and Outcomes in a Tertiary Care Center of a Developing Country in West Africa: A 5 Year Analysis}

\section{Abstract}

Objective: The objective was to determine the Profile of Intensive Care Unit admissions and outcomes in the Lagos University Teaching Hospital (LUTH).

Materials and methods: The Lagos University Teaching Hospital ethical committee provided approval. A retrospective study of all patients admitted into the general Intensive care unit (ICU) of Lagos University Teaching Hospital (LUTH) from $1^{\text {st }}$ of November 2010 to $30^{\text {th }}$ of November 2015 was done. Data were collected from the ICU admission and discharge registers, and data analysis was done using Microsoft Excel 2007.

Results: A total of 647 patients were admitted into the ICU, there were 352 (54.4) males and 295 (45.6) females giving a male to female ratio of 1.2: 1. The young and the middle aged group (20-59 years) accounted for $66.9 \%$ (433) of all the ICU admissions. The study showed that neurosurgical cases accounted for $32.0 \%$ (207) of all admissions into ICU while the lowest was from oral and maxillofacial surgery $0.1 \%$ (1). Severe traumatic brain injury accounted for $77.3 \%$ (160) of all Neurosurgical admission. Mortality rate was $61.4 \%$ (397) in our study and $38.7 \%$ (250) patients survived. There was no correlation between the age of patients and number of deaths across the specialty. Burns and plastics cases accounted for $4.9 \%$ (32) of all admissions into ICU of which $96.9 \%$ (31) of cases had a recorded percentage area of body surface burns. Patients referred from the specialty of Internal medicine made up $18.5 \%$ (119) of the total ICU admissions, while the most common medical indication for admission was Neurological cases $53.8 \%$ (64). Post-operative surgical care across all specialties accounted for $36.6 \%$ (237) of all ICU admission.

Conclusion: Survival rate of patients in our ICU is uncomfortably low. The need to set up a local critical care medicine training program to produce intensive care physicians for the ICUs should be put in place to help improve the outcome of patients. Also, the absence of numerous data in our region on workload, outcome and costs, and the heterogeneity of ICUs, makes it evident that any recommendation about future provision will be highly speculative.

Keywords: Admission; Intensive care unit; Outcome
Poluyi EO, Fadiran OO, Poluyi CO, Alabi EO and Falohun SA

Lagos University Teaching Hospital, Washington, District of Columbia, USA

\section{Corresponding author: Fadiran OO}

\section{Đ sfadiran@gmail.com}

Lagos University Teaching Hospital, Washington, District of Columbia, USA.

Tel: $2027907833 / 2348021001273$

Citation: Poluyi EO, Fadiran OO, Poluyi CO, et al. Profile of Intensive Care Unit Admissions and Outcomes in a Tertiary Care Center of a Developing Country in West Africa: A 5 Year Analysis. J Intensive \& Crit Care 2016, 2:3.

\section{Introduction}

Intensive care units (ICUs) and multi-disciplinary team management have evolved improving the survival of critically ill patients [1-3]. It is a special department of tertiary hospitals for patients with the most severe and life threatening conditions who constantly require intensive monitoring, support from specialized equipment and easy access to medications in order to maintain normal physiological functions [4]. 
The earliest attempt at grouping unstable patients started in the 1930s in the form of a post-operative recovery room. The concept of intensive care units (ICU) dates back to the epidemic of poliomyelitis in the early 1950s with the use of long term mechanical ventilation [5, 6]. By the 1960's many institutions had developed "respiratory care units" to facilitate the management of patients requiring mechanical ventilation. At the same time, coronary care units were also established for the intensive postoperative care of patients who had undergone cardiac surgery while surgical units managed patients who had undergone major surgical procedures [7].

Today, Intensive care units (ICUs) of most hospitals in developed countries have become separate departments staffed by career intensive care physicians or intensivists from various fields of medicine [5]. In Nigeria, however, ICUs are still part of the anaesthesia department and critical care constitutes a substantial part of the workload and responsibilities of anaesthetists [8]. The ICUs have developed a highly specialized field with variations in their size and capabilities. This variation occurs between regions, countries or states and even hospitals. The types of ICU include general, medical, surgical, neurosurgical, cardiothoracic, paediatric, neonatal, coronary care, burns and trauma [9].

The Intensive care unit of Lagos University Teaching Hospital (LUTH) is a specialized unit that provides exclusive expertise and facilities for care of patients with life threatening illness. It was established in 1990 as a 5-6 bedded compact unit well equipped for critical care at the highest level, located adjacent to the operating theatre complex, though it is presently being renovated. The ICU is staffed by 11 consultant anaesthetists and trainee doctors at various levels of training. There are 23 nursing staffs, 5 of whom are well-trained intensive care nurses.

Data regarding outcome in the ICU is well-documented but insufficient in Africa, although it has been described [10-14]. This study will provide updated information about the recent pattern of admission and outcome in our ICU in LUTH, especially 5 years prior to renovation and concentrate on areas in need of improvement that will benefit patients admitted for ICU care. This will contribute to the literature on the provision of intensive care facilities in Nigeria.

\section{Materials and Methods}

\section{Settings}

This is a 5 year retrospective study in which data on demographic characteristics, diagnosis on admission, nature of intervention and outcome were obtained on all patients admitted into the Intensive care unit (ICU) of Lagos University Teaching Hospital (LUTH) from $1^{\text {st }}$ of November 2010 to 30 $30^{\text {th }}$ of November 2015. The data was obtained from ICU admissions record book. These patients were managed by the anesthetists and the admitting surgeon or physician. The data was recorded on a proforma format sheet designed for the study and data analysis was done using Microsoft Excel 2007.

\section{Results}

A total of 647 patients were admitted into the ICU, there were 352 (54.4) males and 295 (45.6) females giving a male to female ratio of 1.2: 1 (Table 1).

The young and the middle aged group (20-59 years) accounted for $66.9 \%$ (433) of all the ICU admissions while the elderly aged group (60-99 years) accounted for $15.3 \%$ (99) as shown in Table 1. The ages of $1.39 \%$ (9) patients were unknown during their stay in admission, and this was due to incomplete documentation (Table 2).

The study showed that neurosurgical cases accounted for $32.0 \%$ (207) of all admissions into ICU while the lowest was from oral and maxillofacial surgery $0.1 \%$ (1). Internal medicine accounted for $18.5 \%$ (119), Obstetrics \& Gynecology accounted for $15.5 \%$ (100) and Paediatrics accounted for 3.1\% (20) of all admissions into ICU. The total number of deaths recorded in the study was $61.4 \%$ (397), in which Neurosurgery accounted for $34.3 \%$ (136) and Internal medicine, Obstetrics \& Gynaecology and General surgery accounted for $18.6 \%$ (74), $13.1 \%$ (52), and $13.1 \%(52)$ respectively. Oral\& maxillofacial surgery did not record any number of deaths (Figures 1 and 2).

Table 1 Age distribution of patients admitted into ICU (November 2010-November 2015).

\begin{tabular}{|c|c|c|}
\hline Age (Years) & Frequency & Percentage (\%) \\
\hline $0-9$ & 61 & 9.42 \\
\hline $10-19$ & 45 & 7.00 \\
\hline $20-29$ & 121 & 18.70 \\
\hline $30-39$ & 153 & 23.65 \\
\hline $40-49$ & 87 & 13.44 \\
\hline $50-59$ & 72 & 11.13 \\
\hline $60-69$ & 60 & 9.27 \\
\hline $70-79$ & 27 & 4.17 \\
\hline $80-89$ & 7 & 1.07 \\
\hline $90-99$ & 5 & 0.76 \\
\hline Unknown age & 9 & 1.39 \\
\hline Total & 647 & 100.0 \\
\hline
\end{tabular}

Table 2 Pattern of admission and deaths according to specialty from November (2010-2015).

\begin{tabular}{|c|c|c|}
\hline Specialty & $\begin{array}{c}\text { Total number of } \\
\text { admission (\%) }\end{array}$ & $\begin{array}{c}\text { Total number } \\
\text { of Deaths (\%) }\end{array}$ \\
\hline Neurosurgery (NSU) & $207(32.0)$ & $\mathbf{1 3 6}(\mathbf{3 4 . 3 )}$ \\
\hline Obstetrics \&Gynaecology & $100(15.5)$ & $\mathbf{5 2 ( 1 3 . 1 )}$ \\
\hline Internal medicine & $119(18.5)$ & $\mathbf{7 4 ( 1 8 . 6 )}$ \\
\hline General Surgery & $90(13.9)$ & $\mathbf{5 2 ( 1 3 . 1 )}$ \\
\hline Cardiothoracic surgery unit (CTSU) & $46(7.1)$ & $\mathbf{2 3 ( 5 . 8 )}$ \\
\hline Burns \& Plastic surgery (BPSU) & $32(4.9)$ & $\mathbf{2 9 ( 7 . 3 )}$ \\
\hline Paediatrics & $20(3.1)$ & $\mathbf{1 2 ( 3 . 0 )}$ \\
\hline Orthopaedics & $13(2.0)$ & $\mathbf{6 ( 1 . 5 )}$ \\
\hline Paediatrics surgery (PSU) & $9(1.4)$ & $\mathbf{7 ( 1 . 8 )}$ \\
\hline Urology & $6(0.9)$ & $\mathbf{4 ( 1 . 0 )}$ \\
\hline Ear, Nose \& Throat surgery (ENT) & $4(0.6)$ & $\mathbf{2 ( 0 . 5 )}$ \\
\hline Oral \& maxillofacial surgery (OMFS) & $1(0.1)$ & $\mathbf{0 ( 0 . 0 )}$ \\
\hline Total & $\mathbf{6 4 7 ( 1 0 0 . 0 )}$ & $\mathbf{3 9 7}(\mathbf{1 0 0 . 0})$ \\
\hline
\end{tabular}




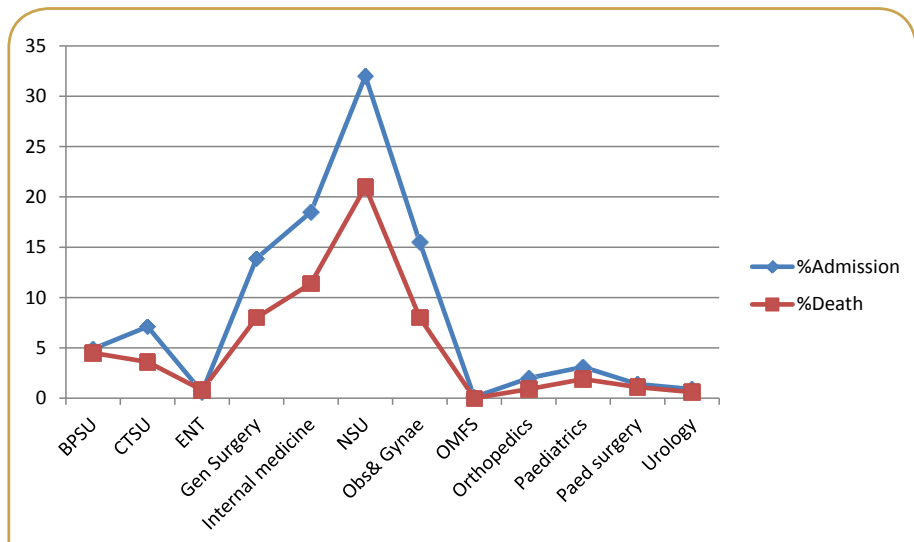

Figure 1 Pattern of admission and deaths according to specialty.

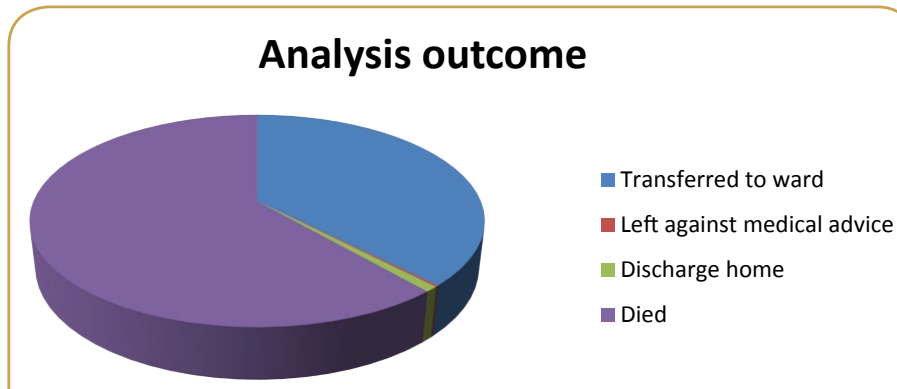

Figure 2 Analysis of outcome.

The study shows $38.7 \%$ (250) patients survived, out of which $97.6 \%$ (244) were transferred to ward from the ICU, $2 \%$ (5) of them were discharged home, $0.2 \%$ (1) left against medical advice while $61.4 \%$ (397) of total admissions died (Figure 3).

Our study showed no correlation between the age of patients and number of deaths across the specialty. The (0-9 years) age group had the highest mortality in the Paediatrics surgery unit (PSU) $100 \%$ and paediatrics department (53.8\%). While the mortality amongst the (70-79 years) group was highest in the orthopaedicunit accounting for $33.3 \%$ of all orthopedic mortalities. The age groups with the highest mortality in Burns and plastics unit were the (30-39 years) age group and (20-29 years) age group accounting for $37.9 \%$ and $24.1 \%$ respectively. Amongst the internal medicine mortalities the percentage in the (60-69 years), (70-79 years) and (80-89 years) age groups were $22.2 \%, 10 \%$ and $4.4 \%$ respectively. While majority of mortality in the Obstetrics and Gynaecology group were in the age range of (30-39 years) $52.9 \%$ and (20-29\%) 33.3\%. Amongst the Neurosurgical mortality the percentage contribution of the age groups (30-39), (40-49), (50-59) and (60-69) years were $19.5 \%, 13.3 \%, 14.8 \%$ and $7.8 \%$ respectively with the (70-79) year age group contributing a percentage mortality of $4.7 \%$. Our study further shows that the mortality across (30-39 year) age group is highest in the General surgery unit $30.4 \%$ (15 cases), Burns and plastics unit (BPSU) 37.9\% (11 cases) and Obstetrics and Gynaecology (O\&G) unit 52.9\% (27 cases) while the highest mortality in the Cardiothoracic surgery unit (CTSU) is across the (0-9 years) age group reaching a percentage of $21.7 \%$ (5). There is an uneven distribution across neurosurgical death cases, more in age group (20-69 years) which accounted for about $75.7 \%$ (96) of neurosurgical death cases (136) in our study (Figure 4).

Severe traumatic brain injury accounted for $77.3 \%$ (160) of all Neurosurgical admission during the study while Brain tumour, spine injury and others accounted for $17.9 \%(37), 2.9 \%(6)$ and $1.9 \%$ (4) respectively of Neurosurgical admission.

Burns and plastics cases accounted for $4.9 \%$ (32) of all admissions into ICU, in which $96.9 \%$ (31) Burns cases had a recorded percentage area of body surface burns. Twenty six (83.9\%) of burns patients who died, had over $50 \%$ of the body surface area affected (Table 3). The total number of death recorded was $93.5 \%$ (29) of all burns admissions, the extent of burn, inhalation injury and sepsis were major mortality indices.

Patients referred from the specialty of Internal medicine made up $18.5 \%$ (119) of the total ICU admissions, while the most common medical indication for admission was Neurological cases $53.8 \%$

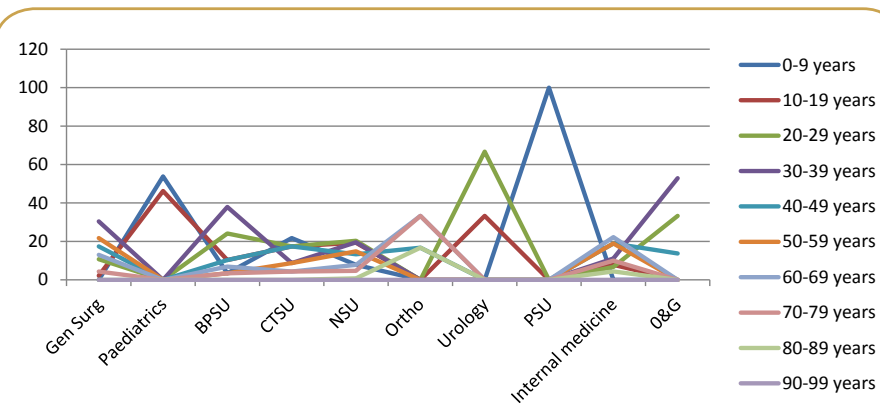

Figure 3 Percentage of death and age distribution across all specialty in our study.

\section{Neurosurgical cases at ICU}

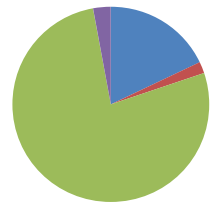

Brain tumour
Others
Severe traumatic brain injury
Spine Injury

Figure 4 Neurological cases at ICU.

*Others: Gunshot injury and carbon monoxide poison

Table 3 Percentage burns distribution of patients admitted and mortality.

\begin{tabular}{|c|c|c|c|}
\hline $\begin{array}{c}\text { \% Body } \\
\text { urface burns }\end{array}$ & $\begin{array}{c}\text { Number of } \\
\text { patients admitted }\end{array}$ & $\begin{array}{c}\text { No of } \\
\text { deaths }\end{array}$ & $\begin{array}{c}\text { No of deaths as \% of } \\
\text { burns patients mortality }\end{array}$ \\
\hline $0-10$ & 0 & 0 & 0 \\
\hline $11-20$ & 0 & 0 & 0 \\
\hline $21-30$ & 1 & 1 & 3.4 \\
\hline $31-40$ & 0 & 0 & 0 \\
\hline $41-50$ & 4 & 4 & 13.8 \\
\hline $51-60$ & 5 & 5 & 17.2 \\
\hline $61-70$ & 6 & 6 & 20.7 \\
\hline $71-80$ & 4 & 4 & 13.8 \\
\hline $81-90$ & 7 & 5 & 17.2 \\
\hline $91-100$ & 4 & 4 & 13.8 \\
\hline Total & 31 & 29 & 99.9 \\
\hline
\end{tabular}


(64) and the most of such were from cerebrovascular accident (CVD) $70.3 \%$ (45) as shown in Table 4 (Figure 5).

Post-operative surgical care across all specialties accounted for $36.6 \%$ (237) of all indications for ICU admission. Exploratory laparotomy (EXP LAP) (Table 5) was the most common indication for post-operative ICU cares in General surgery, while intracranial surgery was the most common indication for Neurosurgery (NSU) post-operative ICU care. The study showed that General surgery accounted for $36.3 \%$ (86) of all post-operative admissions which is followed by Neurosurgery $27.8 \%$ (66) and Oral and maxillofacial surgery (OMFS) $0.4 \%$ (1) accounted for the least post-operative surgical admissions. Obstetrics and Gynaecology (O\&G) accounted for $15.2 \%$ Wh caesarian section (EMCS) $38.9 \%$ (14) and Elective caesarian section (ELCS) $8.3 \%$ (3) were the indications in Obstetrics and Gynaecology post-operative care. Cardiothoracic surgery (CTSU) accounted for $11.4 \%$ (27) of all post-operative admissions, in which Closed tube thoracostomy drainage (CTTD) $29.6 \%$ (8) and Thoracotomy $22.2 \%$ (6) were the most common cardiothoracic procedures. Orthopedics surgery, Paediatrics surgery (PSU) and Urology accounted for $2.5 \%(6), 3.5 \%$ (8) and $2.5 \%$ (6) of post-operative care admissions respectively (Table 5).

All ICU admissions in Oral and maxillofacial surgery (OMFS) $100 \%$ (1) and Urology $100 \%$ (6), and majority in General surgery $95.6 \%$ (86) and Paediatric surgery (PSU) 88.9\% (8) were operative cases. Non operative cases accounted for $68.1 \%$ (141) of Neurosurgery (NSU) and 64\% (64) of Obstetrics and gynecological ICU admissions in our study (Figure 6).

\section{Discussion}

The outcome of intensive care depends not only on the facilities provided in the unit, the skill and timing with which they are administered, but also on the case mix of problems presented by the surgeons and physicians, who make the initial decisions, which results in their patients requiring intensive care [15]. Although, it demands a tremendous amount of time and efforts of the medical and nursing staff to treat and improve survival of the critically ill patients [16].The type and facilities available influences the variety of critical cases that can be handled [9].

Table 4 Indication for admission into ICU from internal medicine.

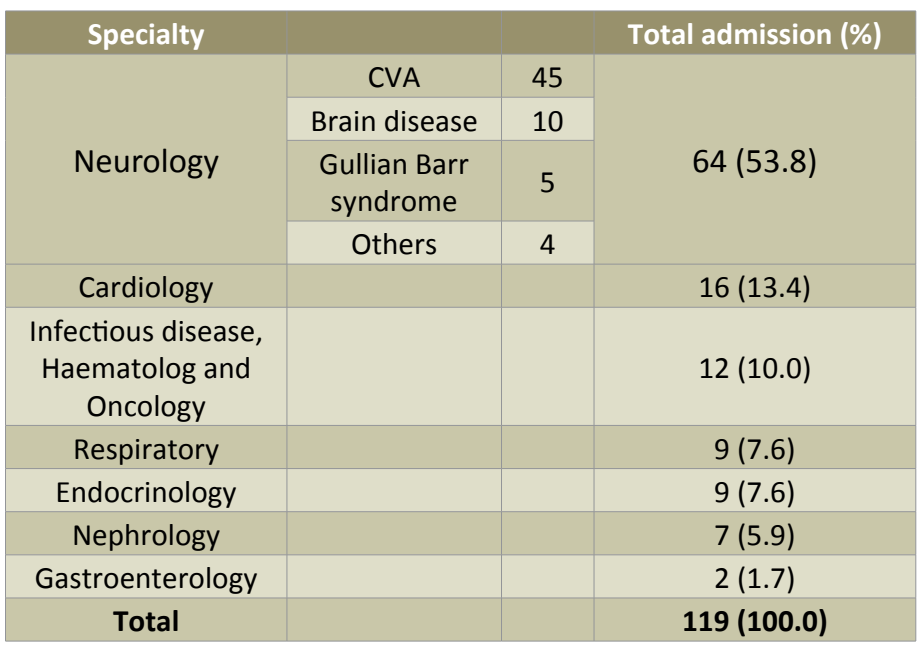

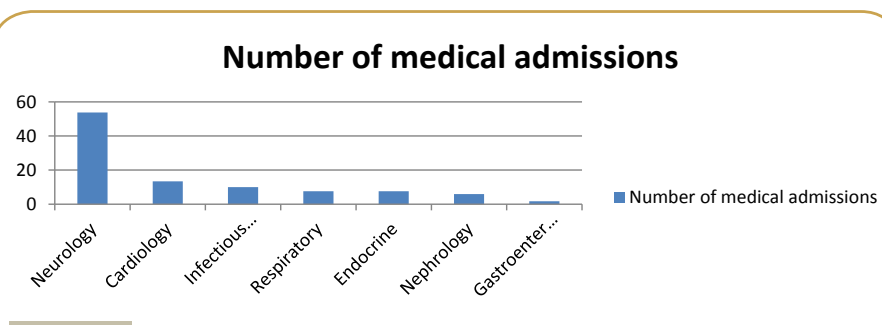

Figure 5 Indication for admission into ICU from internal medicine.

Most of the patients that were admitted in the Lagos university teaching hospital (LUTH) ICU during the period of review belong to the young and middle age group the active and productive segment of the general population accounting for $66.9 \%$ (433) of all the ICU admissions, the result is comparable to a similar report from Jos university teaching hospital (JUTH) [9].

In our study, neurosurgical specialty $32.0 \%$ (207) is observed to be the highest surgical specialty utilizing the ICU bed spaces. This was different from the study done by Mato et al. where the Obstetrics department was the highest specialty utilizing the ICU bed space [17]. This could be attributed to the availability of neurosurgical specialty care that our centre provides.

Our study also shows Severe Traumatic brain injury (TBI) accounting for $77.3 \%$ (160) of all Neurosurgical admission during the study. This agrees with a study done in Britain where high velocity injuries were caused by rapid acceleration and deceleration [18]. In a study by (Adenekan and Faponle) road traffic crashes were responsible for most deaths and major trauma admissions to the ICU [19]. The high prevalence of severe TBI in our study is due to the high level of reckless driving, poor maintenance of the highway and also the availability of a neurosurgical unit in LUTH, one of the very few neurosurgical centres in Lagos State. Management strategy should include increased public enlightenment campaign, enforcement of safety rules and improved pre and in-hospital care of trauma victims [19]. Developing a viable trauma team and separately equipped neurosurgical ICU with well trained staff will help improve the outcome of patients. Our study also shows that brain tumour, spine injury and others (Gunshot injury and carbon monoxide poison) accounted for $17.9 \%$ (37), 2.9\% (6) and $1.9 \%$ (4) respectively of Neurosurgical admission (Figure 4).

Our study shows Paediatrics age group (0-15 years) accounted for $11.1 \%$ (72) of all admissions into ICU, almost similar to a study in New Zealand by McHugh et al. [20], in which their study had an admission rate of $7.4 \%$ for the paediatric age group in their general ICU. This is in contrast with our previous earlier study [21] and that of JUTH [9] where paediatric ICU admission rate were over $28 \%$, and $22.1 \%$ respectively. This reduction in our paediatrics admission into ICU could be attributed to the commissioning of the Children Emergency building (January 2010) where fragile paediatrics cases are attended to promptly and well manage at a very early stage.

Our study shows a mortality rate of $61.4 \%$ (397), which is slightly similar to our previous study [21] where the overall mortality rate 
was $69 \%$ but in contrasts with previous studies in this country which showed overall mortality rates ranging from $30-37.6 \%$ $[8,22,23]$. A lower mortality rate was observed by Mato et al. (24.3\%) but in their study over $42 \%$ of admissions into the ICU was non-justifiable as most patients were admitted into ICU for lack of bed space in the general wards and for better comfort [17]. The mortality rate in our study compares favourably with others in the country; it is higher than those reported in the developed world, where mortality figures of $18-24 \%$ have been quoted $[24,25]$. Our study also shows no correlation between the age of patients and number of deaths across the specialty (Figure 3).

Burn injuries have assumed alarming levels in Nigeria. While it has been noted that mortality from burn injury worldwide is on the decline, it still represents a significant contributor of morbidity and mortality in Nigeria [26]. Burns and plastics cases accounted for $4.9 \%$ (32) of all admissions into our ICU, in which $96.9 \%$ (31) Burns cases had percentage body surface burns recorded. Twenty six $(83.9 \%)$ of burns patients who died, had over $50 \%$ of the body surface area affected (Table 3). This is in contrast with the study in University Teaching Hospital, Ilorin, Nigeria [27] where the lowest percentage of body surface area (BSA) burned in patients that were admitted was $20 \%$. The total number of death recorded was $93.5 \%$ (29) of all our burns admissions. The extent of burn, inhalation injury and sepsis were major mortality indices. These patients may have developed pharyngeal and laryngeal oedema, with upper airway obstruction. Although, it is our practice to perform tracheal intubation early in order to prevent upper airway obstruction, supplemental oxygen is also administered to these patients in our centre but most of the patients present very late. Fire outbreaks related to inappropriate access and storage of petroleum products accounted for most of the burns cases admitted during the period studied but the mortality from this cause was as high as $93.5 \%$ (29).This was probably because most of the cases were of the type described as' horrendous burns injuries from fire outbreaks caused by adulterated fuels [28]. This is in contrast with the pattern seen in the developed world where majority of burn injuries occur in the home [29]. Our previous study [21] and that of Jos University Teaching Hospital (JUTH) [9] recorded no admissions for Burns in the ICU. However, a 4 year retrospective study at Ogun State University Teaching Hospital (OSUTH) [8], showed that 14 (6.8\%) of all the ICU admissions were for Burns and mortality rate for the affected patients was $35.7 \%$. The mortality rate for burns patients admitted in the ICU at University of Port Harcourt Teaching Hospital (UPTH) was more than twice that of OSUTH. Severity of burn injuries suffered by the UPTH patients may partly account for the big difference [28]. However, level of equipment and expertise of staff of these ICU (OSUTH and UPTH) in the care of burns victims could also have contributed to the difference in outcomes.

Our review showed a high ICU utilization by Neurosurgical patients, especially following operative procedures. This is not a surprise since most of these patients require a highly specialized care that our center provides for early identification and intervention in the event of sudden deterioration in clinical status. This is not because the majority of patients in this review did not require its use, but it is mainly due to the inadequate resources available to the ICU as a result of poor health care funding, which is a common feature in a low resource economy like Nigeria.

Patients referred from the specialty of Internal medicine made up $18.5 \%$ (119) of the total ICU admissions, while the most common medical indication for admission was Neurological cases $53.8 \%$ (64) (Figure 5). This is almost similar to a study in Delta state ICU [30] where $20.6 \%$ (196) of all ICU admissions were for 'Medical' problems and that of OSUTH [8] and JUTH [12] which accounted for $14.5 \%$ and $19 \%$ respectively. Amongst medical admissions, our study showed neurological patients accounted for $53.8 \%$ with cerebrovascular accident diseases (CVA) responsible for $70.3 \%$ (45) of these cases, which is in contrast to our previous study [23], where it was tetanus.

Postoperative cases across the various surgical specialties accounted for $36.6 \%$ (237) of all admission into the ICU (Table 5). General surgery accounted for accounted for $36.3 \%$ (86) of all post-operative admissions which was followed by Neurosurgery $27.8 \%$ (66) and Oral and maxillofacial surgery $0.4 \%$ (1) accounted for the least post-operative admissions (Figure 6). This result is in contrast to previous studies done by Isamade et al. [9] and by Bolaji and Kolawale [27].

Obstetrics and Gynaecology accounted for $15.2 \%$ (36) of all postoperative admissions. Most of these patients had obstetrics and gynaecological surgeries due to disorders such as eclampsia, severe pre-eclampsia, severe ante partum haemorrhage and ruptured uterus.

\section{Limitations of the Study}

Although the research has reached its aims there were some unavoidable limitations. First, this is a cross-sectional study and cannot be used to postulate incidence, effects of interventions and follow-up studies. The sampling technique though limited to a tertiary care center would make generalizability of results to the country and West Africa impossibility. This study does not provide other outcome measures that can be used to assess quality of intensive care such as mortality within the first $24 \mathrm{~h}$ and mean number of ICU days of stay per survivor. This is due to measures used to collate data from the records, there is need to include information that would allow recording of this indices in the ICU records. Information on the diagnoses of all diseases present and managed throughout this period is not included in this study which would prove useful when comparing with ICU admission and cases in other studies. Future research should provide information on detailed analysis on the diagnosis of ICU cases in LUTH that can allow comparison with other studies. Due to lack of standardization, comparing efficacy of care with even similar ICU studies in developing countries would be difficult and would be more plausible with a prospective study. Also, further study showing annual mortality indices might shed more light on efficacy of care. The fact that there are limited prior studies on this topic in this institution would make portraying changes in trend of admissions difficult. Future similar studies would be recommended to reveal trends in intensive care admissions. To 
Table 5 Indication for admission into ICU by Post-operative surgical care ( $n=237)$.

\begin{tabular}{|c|c|c|c|}
\hline Specialty & & & $\begin{array}{l}\text { Total number of } \\
\text { operative surgical } \\
\text { admission (\%) }\end{array}$ \\
\hline $\begin{array}{l}\text { Obstetrics } \\
\text { \&Gynaecology }\end{array}$ & $\begin{array}{l}\text { EMCS } \\
\text { ELCS } \\
\text { EXP LAP }\end{array}$ & $\begin{array}{c}14 \\
3 \\
19\end{array}$ & $36(15.2)$ \\
\hline CTSU & $\begin{array}{c}\text { CTTD } \\
\text { Decortication } \\
\text { Lobectomy } \\
\text { Oesophagogastrostomy } \\
\text { Pericardiostomy } \\
\text { Pneumonectomy } \\
\text { Thoracotomy } \\
\text { Vascular surgery }\end{array}$ & $\begin{array}{l}8 \\
4 \\
2 \\
2 \\
2 \\
1 \\
6 \\
2\end{array}$ & $27(11.4)$ \\
\hline ENT & $\begin{array}{l}\text { Adenoid tonsillectomy } \\
\text { Tracheostomy }\end{array}$ & $\begin{array}{l}1 \\
1\end{array}$ & $2(0.8)$ \\
\hline General surgery & $\begin{array}{l}\text { Gunshot wound } \\
\text { exploration } \\
\text { Exploratory Laparotomy } \\
\text { Herniorraphy } \\
\text { Thyroidectomy }\end{array}$ & $\begin{array}{l}12 \\
72 \\
1 \\
1\end{array}$ & $86(36.3)$ \\
\hline Neurosurgery & $\begin{array}{l}\text { Intracranial surgery } \\
\text { Laminectomy }\end{array}$ & $\begin{array}{c}65 \\
1\end{array}$ & $66(27.8)$ \\
\hline OMFS & $\begin{array}{c}\text { Resection of mandibular } \\
\text { tumor }\end{array}$ & 1 & $1(0.4)$ \\
\hline Orthopedics & & & $6(2.5)$ \\
\hline $\begin{array}{l}\text { Paediatrics } \\
\text { surgery }\end{array}$ & & & $8(3.5)$ \\
\hline Urology & & & $6(2.5)$ \\
\hline Total & & & $237(100.0)$ \\
\hline
\end{tabular}

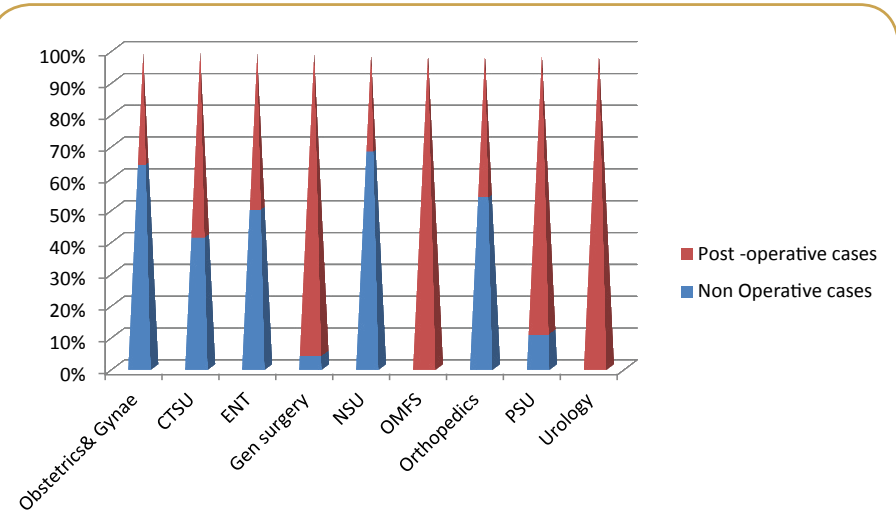

Figure 6 Post-operative and non-operative admission into ICU.

allow generalizability, we would have to collate data from other tertiary care centers in the country and in West Africa as a whole. However this is impossible at the moment because of limited studies, lack of access to data from other tertiary care centers and lack of communication with physicians located in other tertiary care centers. Generalizability was not attempted with this study. Future efforts to encourage research and communication amongst tertiary care centers to create a central database registry would be recommended to make this a possibility.

\section{Conclusion}

Survival rate of patients in our ICU is uncomfortably low, although there are facilities for suctioning, tracheal intubation, mechanical ventilation and patient monitoring. However, irregular supply of electricity and oxygen often hampers the use of these facilities. Facilities for arterial blood gas estimation when available, will improve the monitoring of the ICU patient, especially those on mechanical ventilation and funding should be made available so that the internationally recommended number of ICU beds (relative to the total number of acute admission beds), is available and can be adequately staffed.

The need to set up a local critical care medicine training program to produce intensive care physicians for the ICUs should be put in place. The absence of numerous data in our region on workload, outcome and costs, and the heterogeneity of ICUs, makes it evident that any recommendation about future provision will be highly speculative.

\section{Acknowledgement}

We will like to acknowledge the contributions of all author, coauthors and our mentor Dr. Eyitayo Alabi, consultant orthopedic surgeon Lagos University Teaching Hospital for his, guidance, encouragements and assistance with ethical approval and research.

This research received no specific grant from any funding agency in the public, commercial, or not-for-profit sectors.

\section{Research Questions}

Can this study provide information on the pattern of diseases that characterize tertiary care in Nigeria?

Can this study be used to point out directions of potential expansion and medical infrastructural development in this tertiary care center should the need arise for further development into specialized intensive care units (ICU) units in the future?

Does this study compare with ICU outcomes in similar tertiary care centers in Nigeria and West Africa?

Can the outcomes in this intensive care unit be explained because of the severity of clincal presentation or could it be due to other factors?

Given the fact that this is a retrospective study and no follow up was done, can it adequately define outcome indices?

Can outcomes of this study be compared to similar studies in the past so as to portray a trend in presentation of diseases?

Would other outcome measures such as mean number of ICU days of stay per survivor and annual ICU mortality rate provide more profitable information on the utilization of ICU facilities and outcomes? 


\section{References}

1 Gosselink R, BottJ, Johnson M, Dean E, NavaS, etal. (2008) Physiotherapy for adult patients with critical illness: Recommendations of the European Respiratory Society and European Society of Intensive Care Medicine Task Force on Physiotherapy for Critically III Patients. Intensive Care Med 34: 1188-1199.

2 Van der SM, Beelen A, De Groot IJ (2000) Critical illness polyneuropathy: A summary of the literature on rehabilitation outcome. Disabil Rehabil 22: 808-810.

3 Fan E (2012) Critical illness neuromyopathy and the role of physical therapy and rehabilitation in critically ill patients. Respir Care 57: 933-946.

4 Hinds CJ, Watson D (1996) Planning, organization and management of intensive care. In: A Concise Textbook. 2nd ed. WB Saunders Company Limited, London.

5 Oh TE (1992) Intensive care in Hong kong where now? J Hong kong Med Ass Association 44: 57.

6 Review of intensive care in Hong kong where now? J Hong kong med Ass Association 44: 57.

7 Bjorneboe M, Ibsen B, Astrup P (1955) Active ventilation in treatment of respiratory acidosis in chronic disease of the lungs. Lancet 1955: 901-903.

8 Oyegunle AO, Oyegunle VA (1997) The intensive care unit in a young Nigerian Teaching Hospital. The sagamu (1994-1997) experience. A restropective study. Afr J Ana Int Care 3: 41-43.

9 Isamade ES, Yiltok SJ, Uba AF, Isamade EI, Daru PH (2007) Intensive care unit admissions in the Jos University Teaching Hospital. Nigerian Journal of clinical practice 10: 156-161.

10 Mushin WW, Lunn NJ (1969) The anaesthetist and the intensive care. BMJ 2: 683-684.

11 Second European Consensus Conference on Intensive Care Medicine (1994) Predicting outcome in intensive care unit patients. Int Care World 2: 147-151.

12 Cohen A, Bodenham A, Webster N (1993) A review of 2000 consecutive ICU admission. Anaesthesia 48: 106-110.

13 Bukumirovic V, Bumbasirevic V, Pantic J (1995) An analysis of mortality in intensive care medicine. International Proceedings, Athens, Greece.

14 Feldmann U, Larsen R, George T, Graber S, Schmitt J (2003) A populationbased survey of critical care. Anaethesist 52: 393-408.

15 Intensive care in the United Kingdom: Report from the King's Fund panel. Anaesthesia 44: 428-431.
16 Chalya PL, Gilyoma JM, Dass RM, Mchembe MD, Matasha M, et al. (2011) Trauma admissions to the Intensive Care Unit at a reference hospital in Northwestern Tanzania. Scand J Trauma Resusc Emerg Med 19: 61.

17 Mato CN, Onwuchekwa AC, Aggo AT (2009) Pattern of admission to the University of Portharcourt Teaching Hospital (UPTH) Intensive Care Unit-A 10 year analysis. South Am J Crit Care 25: 10.

18 Helmy A, Vizcaychipi M, Gupta AK (2007) Traumatic brain injury: Intensive care management. Br J Anaesth 99: 32-42.

19 Adenekan AT, Faponle AF (2009) Trauma admissions to the ICU of a tertiary hospital in a low resource setting. Afr J Anaesth Intensive Care 9: 5-9.

20 McHugh GJ, Hicks PR (1999) Paediatric admissions to the general intensive care unit at Palmerston north hospital. Crit Care Resusc 1: 234-238.

21 Kushimo OT, Okeke Cl, Ffoulkes-Crabbe DJ (1988) Paediatric admission into the intensive care unit of lagos university teaching hospital. Nig Qt Hosp J Med 8: 52-55.

22 Oji A (1987) Development of an Intensive Care Unit: At Jos University Teaching Hospital (JUTH) from 1982 to 1985 . W. Unit. At University Teaching Hospital (JUTH) from 1982 to 1985. W Afr J Med 6: 91-98.

23 Oke DA (2001) Medical admission into the intensive care unit of the Lagos University Teaching Hospital. The Nigerian Postgraduate Medical Journal 8: 179-182.

24 Dragsted L, Qvist J, Madsen M (1989) Outcome from intensive care II. A 5-year study of 1308 patients: Short-term outcome. European Journal of Anaesthesiology 6: 131-144.

25 Ridley S, Jackson R, Findlay J, Wallace P (1990) Long term survival after intensive care. British Medical Journal 301: 1127-1130.

26 Dongo $A E$, Irekpita $E E$, Oseghale LO, Ogbebor $C E$, Iyamu $C E$, et al. (2007) A five year review of burn injuries in Irrua. BMC Health Serv Res 7: 171.

27 Bolaji BO, Kolawole IK (2005) The intensive care unit of the University Teaching Hospital, Ilorin, Nigeria: A ten year review (1991-2001). Southern African Journal of Anaesthesia and Analgesia 11: 146-150.

28 Eke N (2008) Epidemic of trauma: Preventive and social medicine should find relevance (editorial). Port Harcourt Medical Journal (PMJ) 2: 182-183.

29 Muller MJ, Herndon DN (1994) The challenge of burns. Lancet 343 : 216-220.

30 Ebirim L, Ojum S (2012) Outcome of trauma admissions in an intensive care unit in the Niger Delta region of Nigeria. The Internet Journal of Critical Care and Emergency Medicine 12: 1. 